\title{
Cannabinoid CB1 and dopamine D1 receptors partnership in the modulation of emotional neural processing
}

\author{
Irit Akirav ${ }^{1 *}$ and Liana Fattore ${ }^{2}$ \\ Department of Psychology, University of Haifa, Haifa, Israel \\ 2 CNR Institute of Neuroscience - Cagliari, National Research Council of Italy, Cittadella Universitaria di Monserrato, Cagliari, Italy \\ *Correspondence: irit.akirav@gmail.com
}

\section{A commentary on}

The dopamine and cannabinoid interaction in the modulation of emotions and cognition: assessing the role of cannabinoid CB1 receptor in neurons expressing dopamine $\mathrm{D} 1$ receptors

by Terzian, A., Drago, F., Wotjak, C. T., and Micale, V. (2011). Front. Behav. Neurosci. 5:49. doi: 10.3389/fnbeh.2011.00049

The contribution of dopamine and cannabinoid neurotransmission in emotional brain circuits regulating motivational and emotional neural processing has been well acknowledged by both animal and clinical studies (LeDoux, 2000; Laviolette and Grace, 2006). The endocannabinoid system has arisen as part of the complex circuitry that regulates stress and as a crucial mediator of emotional learning (for a comprehensive review see Viveros et al., 2005). The idea that this system is involved in the control of emotions is rooted in the fact that Cannabis sativa is used recreationally, mainly for its euphoric effects. The dopamine (DA) neurotransmitter system is significantly crucial for the neural processing of motivational and emotionally salient information (Wise, 2004). Yet, less is known about the functional interaction between cannabinoid and dopaminergic receptors in the control of emotional behavior. Much of our understanding has been improved only recently by studies using knockout $(\mathrm{KO})$ animals (Micale et al., 2009; Ortega-Alvaro et al., 2011; Thanos et al., 2011), behavioral approaches (Ramiro-Fuentes and Fernandez-Espejo, 2011; Zarrindast et al., 2011), or neuroanatomical and electrophysiological techniques (Chiu et al., 2010).

In an intriguing article of the Special Issue "The endocannabinoid system: a key modulator of emotions and cognition" published in Frontiers in Behavioral Neuroscience, Terzian and colleagues provide the first evidence for a physiological cross-talk between the cannabinoid CB1 receptors (CB1Rs) and the dopamine D1 receptors (D1Rs) in the modulation of depression-like behavior, social skills, and fear conditioning. Specifically, these authors examined the responses of conditional CB1 mutant mice genetically selected for the absence of CB1Rs exclusively in neurons containing D1Rs receptors (D1-CB1 KO mice), in a battery of behavioral tests, and reported the following interesting results. First, when compared to their WT counterparts, D1-CB1 KO mice displayed similar performance in the social novelty, the elevated plus maze, and the light/dark test (all paradigms evaluating different aspects of unconditioned anxiety), but spent more time on grooming activity and showed less social interaction when tested under low aversive conditions. By measuring the anxiety-like profile of these animals using different tests, authors thus disentangled different components of the anxiety state, bringing to light the specific role of CB1-D1 receptors in modulating emotional states under conditions of stress-induced conflict/frustration (grooming behavior) or inescapable situations (social interactions). Secondly, D1-CB1 KO mice showed lower sucrose consumption than WT mice, a behavior reminiscent of a mild anhedonia-like state (commonly associated with depression). However, the finding that such a difference disappears on the second day of testing does not support a depressive-like behavioral phenotype, as also suggested by the observation that KO mice performed as WTs in the forced swim test (commonly used to evaluate animals' behavioral despair). Finally, in the fear conditioning task (a fear-related memory test involving a strong mnemonic component), D1-CB1 KO mice showed significantly increased auditory-cued and contextual fear responses, which is not surprising when considering the important role of DA receptors in fear adaptation processes (El-Ghundi et al., 2001; de la
Mora et al., 2010) and that of CB1 receptors in fear alleviation (Marsicano et al., 2002; Kamprath et al., 2006).

The main outcome of this study is the demonstration that CB1Rs and D1Rs cooperate for the control of a negative affect. This implies that D1R and CB1R signaling systems may mediate overlapping pharmacological responses in clinically important brain areas that mediate diseases, such as Parkinson and epilepsy, in which these two classes of receptors have been reported to strictly interact (Ferrer et al., 2003; Gangarossa et al., 2011).

Although limited by potential compensatory mechanisms that may take place during development, these conditional animals represent a precious tool for investigating whether $\mathrm{CB} 1$ and $\mathrm{D} 1$ receptors also interact in modulating other brain circuits (motivation, reward) and behavioral traits (impulsivity/compulsivity), which may contribute to the development of several disorders (i.e., binge eating disorder). The involvement of the two receptor systems in motivational and emotional neural processing phenomena also suggests that their interaction might be implicated in other neuropathologies such as schizophrenia and addiction (Grace, 1995, 2000; Zavitsanou et al., 2004; Semple et al., 2005).

Perhaps the most robust effect demonstrated by Terzian and colleagues involves the enhancement of conditioned fear and the possible attenuation of extinction learning. This is an important step in advancing our knowledge on the functional interaction between D1Rs and CB1Rs in emotional neural processing and specifically fear adaptation. However, further studies are required to clarify the mechanisms underlying cannabinoids modulation of the DAergic system. For example, it needs to be determined what are the specific neuronal circuits mediating the effects on fear retrieval and fear adaptation in the D1-CB1 $\mathrm{KO}$ mice. Another issue to focus on is short- 
and long-term extinction in these mutant mice. The ability to extinguish emotional responses in the face of a no-longer relevant conditioned cue is an essential part of a healthy emotional memory system (Charney et al., 1993) and deficits in fear extinction are thought to contribute to anxiety disorders such as post-traumatic stress disorder (PTSD). It has been consistently demonstrated that CB1R-deficient mice and $\mathrm{CB} 1 \mathrm{R}$ antagonists block fear extinction. The results by Terzian et al. (2011) suggest that this may also be the case with the D1-CB1 KO mice. This should be carefully examined as it is a clinically relevant issue to ask whether or not a stimulation of D1R-CB1R signaling might accelerate extinction of fear and hence, might be therapeutically effective in the treatment of anxiety disorders, particularly PTSD.

In conclusion, findings here reported by Terzian and colleagues represent an appealing topic of investigation from both pharmacological and pharmaceutical points of view in that it provides a rationale of developing in the future chemical compounds that, by manipulating simultaneously both the D1Rs and CB1Rs, may ameliorate negative and aversive emotional states.

\section{REFERENCES}

Charney, D. S., Davis, M., Deutch, A. Y., Krystal, J. H., and Southwick, S. M. (1993). Psychobiologic mechanisms of posttraumatic stress disorder. Arch. Gen. Psychiatry 50, 295-305.

Chiu, C. Q., Puente, N., Grandes, P., and Castillo, P. E. (2010). Dopaminergic modulation of endocannabinoid-mediated plasticity at GABAergic synapses in the prefrontal cortex. J. Neurosci. 30, 7236-7248.

de la Mora, M.P., Gallegos-Cari,A.,Arizmendi-García,Y., Marcellino, D., and Fuxe, K. (2010). Role of dopamine receptor mechanisms in the amygdaloid modulation of fear and anxiety: structural and functional analysis. Prog. Neurobiol. 90, 198-216.
El-Ghundi, M., O’Dowd, B. F., and George, S. R. (2001). Prolonged fear responses in mice lacking dopamine D1 receptor. Brain Res. 892, 86-93.

Ferrer, B., Asbrock, N., Kathuria, S., Piomelli, D., and Giuffrida, A. (2003). Effects of levodopa on endocannabinoid levels in rat basal ganglia: implications for the treatment of levodopa-induced dyskinesias. Eur. J. Neurosci. 18, 1607-1614.

Gangarossa, G., Di Benedetto, M., O’Sullivan, G. J., Dunleavy, M., Alcacer, C., Bonito-Oliva, A., Henshall, D. C., Waddington, J. L., Valjent, E., and Fisone, G. (2011). Convulsant doses of a dopamine D1 receptor agonist result in Erk-dependent increases in Zif268 and Arc/Arg3.1 expression in mouse dentate gyrus. PLoS ONE 6, e19415. doi: 10.1371/journal. pone.0019415

Grace,A.A. (1995). The tonic/phasic model of dopamine system regulation: its relevance for understanding how stimulant abuse can alter basal ganglia function. Drug Alcohol Depend. 37, 111-129.

Grace,A.A. (2000). Gating of information flow within the limbic system and the pathophysiology of schizophrenia. Brain Res. Brain Res. Rev. 31, 330-341.

Kamprath, K., Marsicano, G., Tang, J., Monory, K., Bisogno, T., Di Marzo, V., Lutz, B., and Wotjak, C. T. (2006). Cannabinoid CB1 receptor mediates fear extinction via habituation-like processes. J. Neurosci. 26, 6677-6686.

Laviolette, S. R., and Grace, A. A. (2006). The roles of cannabinoid and dopamine receptor systems in neural emotional learning circuits: implications for schizophrenia and addiction. Cell. Mol. Life Sci. 63, 1597-1613.

LeDoux, J.E. (2000). Emotion circuits in the brain. Annu. Rev. Neurosci. 23, 155-184.

Marsicano, G., Wotjak, C. T., Azad, S. C., Bisogno, T., Rammes, G., Cascio, M. G., Hermann, H., Tang, J., Hofmann, C., Zieglgänsberger, W., Di Marzo, V., and Lutz, B. (2002). The endogenous cannabinoid system controls extinction of aversive memories. Nature 418, 530-534.

Micale, V., Cristino, L., Tamburella, A., Petrosino, S., Leggio, G. M., Drago, F., and Di Marzo, V. (2009). Altered responses of dopamine D3 receptor null mice to excitotoxic or anxiogenic stimuli: possible involvement of the endocannabinoid and endovanilloid systems. Neurobiol. Dis. 36, 70-80.

Ortega-Alvaro, A., Aracil-Fernández, A., GarcíaGutiérrez, M. S., Navarrete, F., and Manzanares, J. (2011). Deletion of CB2 cannabinoid receptor induces schizophrenia-related behaviors in mice. Neuropsychopharmacology 36, 1489-1504.
Ramiro-Fuentes, S., and Fernandez-Espejo, E. (2011). Sensitization to cocaine is inhibited after intra-accumbal GR103691 or rimonabant, but it is enhanced after co-infusion indicating functional interaction between accumbens $\mathrm{D}(3)$ and CB1 receptors. Psychopharmacology (Berl.) 214, 949-959.

Semple, D. M., McIntosh, A. M., and Lawrie, S. M. (2005). Cannabis use as a risk factor for psychosis: systematic review. J. Psychopharmacol. 19, 187-194.

Terzian, A. L., Drago, F., Wotjak, C. T., and Micale, V. (2011). The dopamine and cannabinoid interaction in the modulation of emotions and cognition: assessing the role of cannabinoid CB1 receptor in neurons expressing dopamine D1 receptors. Front. Behav. Neurosci. 5:49. doi: 10.3389/fnbeh.2011.00049

Thanos, P. K., Gopez, V., Delis, F., Michaelides, M., Grandy, D. K., Wang, G. J., Kunos, G., and Volkow N. D. (2011). Upregulation of cannabinoid type 1 receptors in dopamine D2 receptor knockout mice is reversed by chronic forced ethanol consumption. Alcohol. Clin. Exp. Res. 35, 19-27.

Viveros, M. P., Marco, E. M., and File, S. E. (2005). Endocannabinoid system and stress and anxiety responses. Pharmacol. Biochem. Behav. 81, 331-342.

Wise, R. A. (2004). Dopamine, learning and motivation. Nat. Rev. Neurosci. 5, 483-494.

Zarrindast, M. R., Mahboobi, S., Sadat-Shirazi, M.S., and Ahmadi, S. (2011). Anxiolytic-like effect induced by the cannabinoid CB1 receptor agonist, arachydonilcyclopropylamide (ACPA), in the rat amygdala is mediated through the D1 and D2 dopaminergic systems. J. Psychopharmacol. 25, 131-140.

Zavitsanou, K., Garrick, T., and Huang, X. F. (2004). Selective antagonist SR141716A binding to cannabinoid CB1 receptors is increased in the anterior cingulated cortex in schizophrenia. Prog. Neuropsychopharmacol. Biol. Psychiatry 28, 355-360.

Received: 27 September 2011; accepted: 28 September 2011; published online: 13 October 2011.

Citation: Akirav I and Fattore L (2011) Cannabinoid CB1 and dopamine D1 receptors partnership in the modulation of emotional neural processing. Front. Behav. Neurosci. 5:67. doi: 10.3389/fnbeh.2011.00067

Copyright $(\odot 2011$ Akirav and Fattore. This is an open-access article subject to a non-exclusive license between the authors and Frontiers Media SA, which permits use, distribution and reproduction in other forums, provided the original authors and source are credited and other Frontiers conditions are complied with. 